\title{
Self-compacting fine-grained concretes with compensated shrinkage
}

\author{
Lev Alimov ${ }^{1}$, Igor Kharchenko ${ }^{2 *}$, and Viktor Voronin ${ }^{1}$ \\ ${ }^{1}$ Moscow state university of civil engineering, Yaroslavskoye shosse, 26, Moscow, Russia, 129337 \\ ${ }^{2}$ Moscow state university of civil engineering, Yaroslavskoye shosse, 26, Moscow, Russia, 129337
}

\begin{abstract}
This paper substantiates the efficiency of application of finegrained concrete for erection of cast-in-place concrete and reinforced concrete structures of different purpose. On the basis of analysis of experimental research results it was established that the introduction of microfillers with expansion effect to composite binder allows not only improving the rheological properties of fine-grained concrete, but also decreasing of value of shrinkage strain and improving of concrete crack resistance and durability. The analysis of the results of industrial use of fine-grained concretes with compensated shrinkage is given.
\end{abstract}

\section{Introduction}

Almost in all regions of Russia where $80 \%$ of construction capacities are concentrated, there is an acute deficiency of broken stone for production of qualitative concrete and reinforced concrete structures. Herewith, the fraction of transportation costs in final costs of commercial concrete in different regions reaches $50 \%$. In this connection the large-scale implementation in construction practice of non-broken-stone or fine-grained concrete is the crucial task of modern cast-in-place construction. However, there exist a number of factors restraining the application of fine-grained concretes for erection of cast-in-place concrete and reinforced concrete structures. These factors include excessive cement consumption, excessive shrinkage, low crack resistance, excessive porosity and deformability, etc. Besides, fine-grained concrete mixes prepared with no account of their rheological properties possess low processibility, which affects the quality of structures.

Improvement of quality and efficiency of application of fine-grained concrete mixes may be provided by means of implementation of principles underlying the technology of self-compacting concretes (SCC) that find wide application in foreign construction practice [1-5].

Nowadays, SCC didn't come into common use yet in Russia, but there are lots of examples of its effective application.

It is known that self-compacting concrete mixes may be obtained only if its separate components, particularly fine-ground mineral additives, are agreed in grain-size composition. Introduction of fine-grained and finely dispersed microfillers into

*Corresponding author: iharcenko@mail.ru 
composition of binders allow substantial increase in strength characteristics and durability of concretes $[6,7]$. One of effective mineral fillers essentially increasing quality of concrete mix and concrete is the microsilica dust, as well as fine-grained carbonate flour. Introduction of these fillers into concrete composition allows both filling of intergranular openings in cement matrix and substantial improvement of contact area between the cement stone and the filler. $[8,9,10]$

Optimum utilization of microfillers along with the application of highly effective superplasticizers is the primary prerequisite for obtaining of high-quality fine-grained selfcompacting concretes [11 - 15].

At production of self-compacting concretes (SCC) composite multicomponent binders are used, which microstructure includes microparticles of cement clinker, mineral-based microfillers with different fineness and hydraulicity, water, common pore structure.

\section{Materials and mixture composition}

Experimental research of the effect of mineralogical composition of Portland cement and composite binders on its basis on rheological properties of fine-grained concrete of different strength grades were performed with the application of polycarboxylate superplasticizers (PCE) of different type ("Sika Visko Crete"). On the basis of analysis of obtained results the defining effect of $\mathrm{C}_{3} \mathrm{~A}$ on the efficiency of PCE application was established. Also the research of properties of binder solutions at different content of $\mathrm{C}_{3} \mathrm{~A}$ in cement component was conducted. According to $\mathrm{C}_{3} \mathrm{~A}$ content the cements of three types were applied:

- ordinary Portland Cement type CEM I $42.5 \mathrm{~N}$ with $\mathrm{C}_{3} \mathrm{~A}<4 \%$;

- ordinary Portland Cement type CEM I $42.5 \mathrm{~N}$ with $4 \%<\mathrm{C}_{3} \mathrm{~A}<6 \%$;

- ordinary Portland Cement type CEM I $42.5 \mathrm{~N}$ with $\mathrm{C}_{3} \mathrm{~A}>7 \%$.

For optimization of binder and fine-grained concrete properties the concrete mix was added with microfillers with different degree of dispersion and mineral composition. Different grades of fine-grained microfiller on the basis of microcement with expansive additive (MEA) possessing the ability to independent hydraulic hardening were used as hydraulically active microfillers. MEA has constant and smoothly changing grain-size composition and stable chemical and mineralogical composition.

By grain-size composition МСГТ is divided into 3 basic grades restricting the maximum size of grains not exceeding weight percentage of $\mathrm{d} 95$ :

- MEA-Extra (E) - d95 $<5,5 \mu \mathrm{m}$

- MEA-Ultra (U) - d95 <8,5 $\mu \mathrm{m}$

- MEA-Standard (S) $-\mathrm{d} 95<12,5 \mu \mathrm{m}$

The parameters characterizing different MEA grades by the degree of independent hydraulicity and mineral composition are presented in Table 1.

Table 1. Different grades of fine-grained microfiller applied in composite binders with expansive additive (MEA).

\begin{tabular}{|l|c|}
\hline \multicolumn{1}{|c|}{ Type } & $\begin{array}{c}\text { Ability to independent hydraulic hardening and } \\
\text { strength gain, \% }\end{array}$ \\
\hline $\begin{array}{l}\text { Ordinary Portland Cement type } \\
\text { CEM I 42.5 N }\end{array}$ & 100 \\
\hline $\begin{array}{l}\text { Microcement with expansive } \\
\text { additive - Standard (MEA-S) }\end{array}$ & 42 \\
\hline $\begin{array}{l}\text { Microcement with expansive } \\
\text { additive - Ultra (MEA-U) }\end{array}$ & 64 \\
\hline
\end{tabular}




\begin{tabular}{|l|c|}
\hline $\begin{array}{l}\text { Microcement with expansive } \\
\text { additive - Extra (MEA-E) }\end{array}$ & 102 \\
\hline
\end{tabular}

The results of parallel tests on electronic viscosimeter for determination of cement paste viscosity with different content of microfillers were considered.

\section{Results}

The results of research of indices of viscosity and shear resistance of binder solution with adding of different microfillers are presented in fig. 1

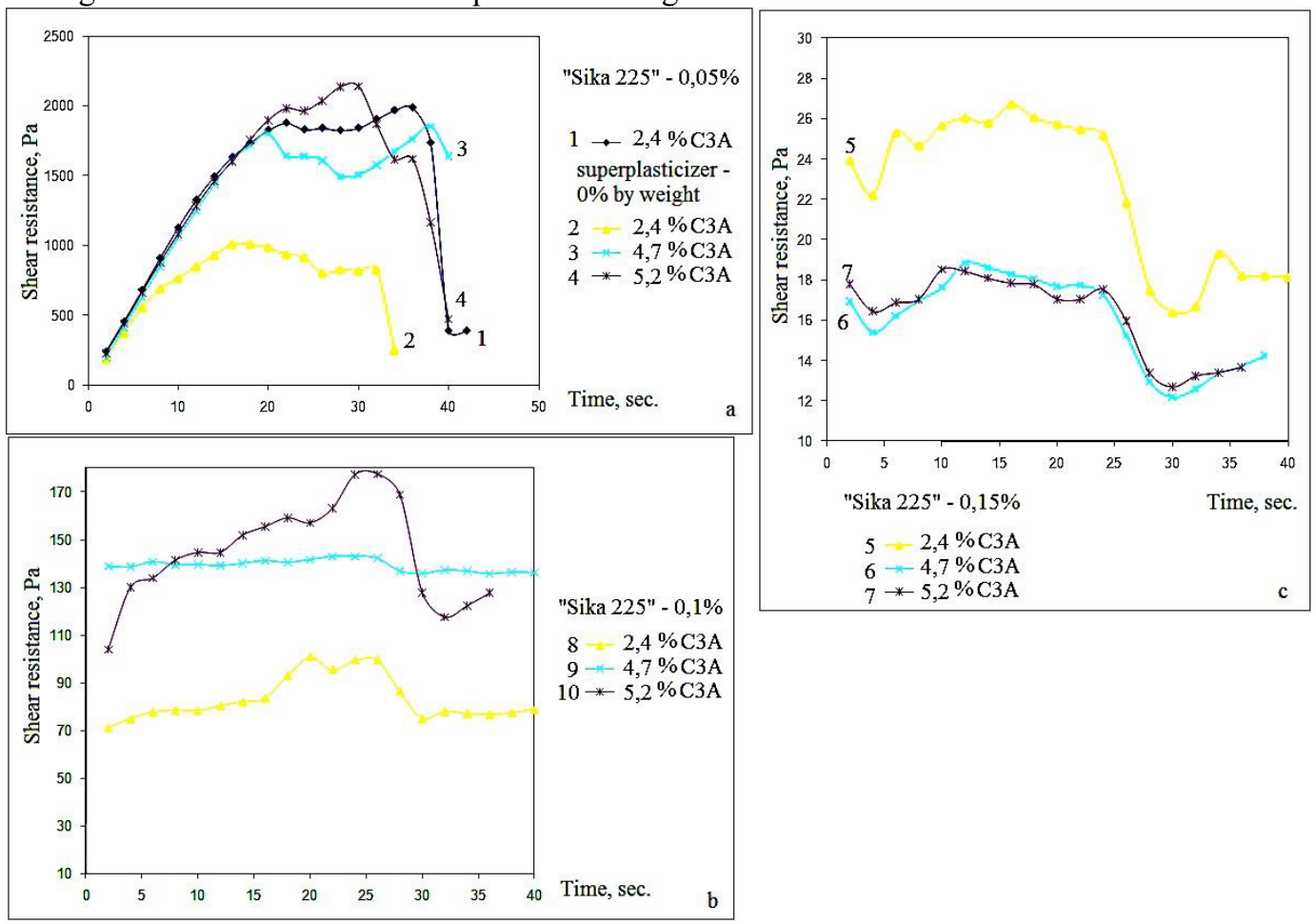

Fig.1. The effect of $\mathrm{C}_{3} \mathrm{~A}$ content in Portland cement on superplasticizer efficiency: $a, b$ and $c$-with superplasticizer content of 0,$05 ; 0,1$ and $0,15 \%$, respectively.

As it seen from fig.1, with the increase of tricalcium aluminate $\left(\mathrm{C}_{3} \mathrm{~A}\right)$ content in binder the efficiency of superplasticizer decreases (Table 2).

Table 2. The dependence of shear resistance from the content $\mathrm{C}_{3} \mathrm{~A}$ and Sika225.

\begin{tabular}{|c|c|c|c|}
\hline Sample No. & $\mathbf{C}_{\mathbf{3}} \mathbf{A}, \boldsymbol{\%}$ & $\begin{array}{c}\text { Superplasticizer } \\
\text { PCE Sika 225, \% }\end{array}$ & Shear resistance, Pa \\
\hline 1 & 2,4 & 0 & 1884 (standard) \\
\hline 2 & 2,4 & 0,05 & 903,64 \\
\hline 3 & 4,2 & 0,05 & 1660,091 \\
\hline 4 & 7,5 & 0,05 & 2002,714 \\
\hline 8 & 2,4 & 0,1 & 91,186 \\
\hline
\end{tabular}




\begin{tabular}{|c|c|c|c|}
\hline 9 & 4,2 & 0,1 & 140,889 \\
\hline 10 & 7,5 & 0,1 & 158,236 \\
\hline 5 & 2,4 & 0,15 & 25,315 \\
\hline 6 & 4,2 & 0,15 & 18,010 \\
\hline 7 & 7,5 & 0,15 & 17794 \\
\hline
\end{tabular}

It was found out that at exceeding of certain limit of superplasticizer dosage, the influence of aluminate constituent on consistency of "binder-water" system becomes negligible (mixtures 5, 6, 7). Test results demonstrate that the maximum degree of efficiency belongs to hyperplasticizer Sika ViscoCrete - 225, which was further used.

The distinctive feature of MEA is the reproducible smooth grain-size composition at high dispersion degree and stable mineralogical composition.

During experimental research as particulate filler was used MEA on the basis of Portland cement clinker, as well as the blast-furnace slag, which possesses high resistance under conditions of sulfate corrosion and is widely used for impregnation injection of soils, injection of foundation structures, brickwork, remediation of waterworks and subsurface structures, stabilizing additive for concretes. In particular, the meaning of MEA microfillers in composite binder shows up in the reduction of composition water demand at the expense of substitution of free water in intergranular space (Fig. 2).

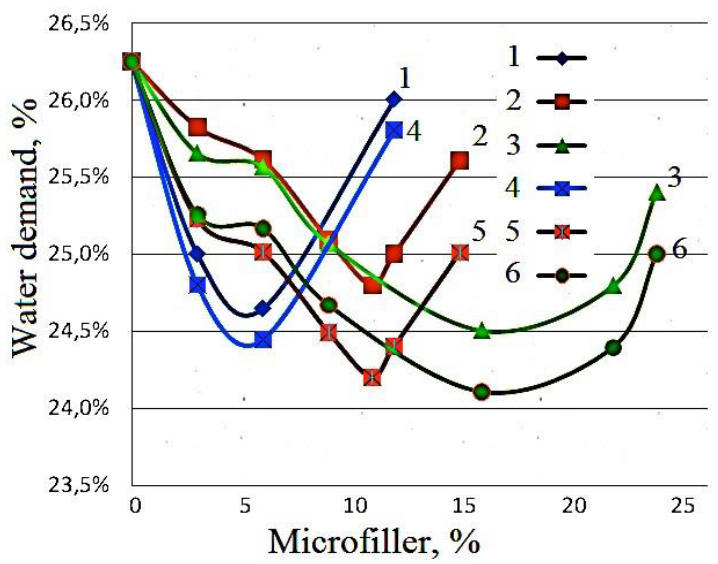

Fig. 2. The effect of microfiller consumption on composite filler water demand ( 1 - Standard, 2 Ultra, 3 - Extra with expansive additive; 4, 5, 6 - the same, but without expansive additive).

Fig.2 shows the effect of microfiller consumption in composite binder on its water demand. Depending on microfiller fineness its content in binder varies from $7 \%$ to $19 \%$ : $7 \%$ - the most coarse with $\mathrm{d} 95<12,5 \mu \mathrm{m}$ (Standard), and 19\% - the finest with $\mathrm{d} 95<6 \mu \mathrm{m}$ (Extra).

At introduction to composite binder of microfiller with expansive additive the minimum water demand is provided at its content in composite binder of not more than $10 \%$. At application of microfiller without expansive additive its optimum consumption increases up to $15 \ldots 17 \%$.

Strength gain for molded samples with composite binder varies in the range from 7 to $27 \%$ relative to use of initial cement CEM I $42,5 \mathrm{~N}$ at the age of 28 days.

Similarly, water demand is reduced at application of composite binder in fine-grained concrete composition. (Fig. 3) 

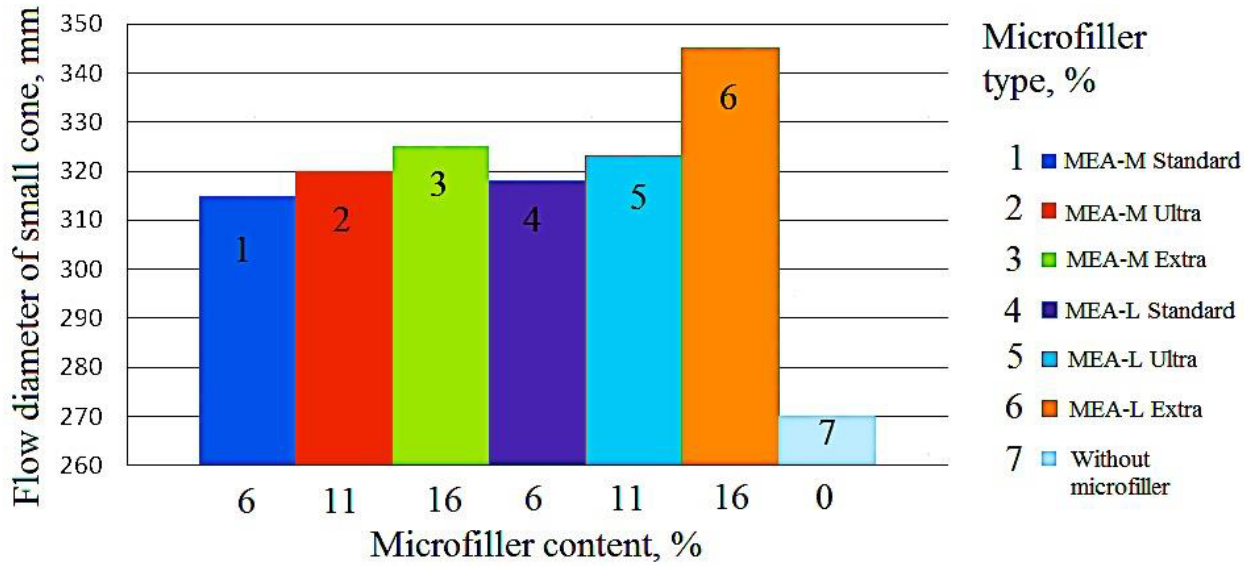

Fig.3. The effect of microfiller on mix flowability at $\mathrm{W} / \mathrm{B}=0,37$

Fig. 3 represents the change of flowability of fine-grained concrete with microfiller as compared to composition without additives. Fine-grained concrete with composite binder has substantially higher flowability at the expense of free water release from intergranular space. Herewith, fine-grained concrete with Extra microfiller possesses maximum flowability, which is explained with its maximum ability to fill intergranular space with displacement of maximum quantity of free water from intergranular space.

As the result of conducted experimental research was extablished the dependence W/C ratio of fine-grained concrete on the type and amount of microfiller in composite binder composition. Fig.4.

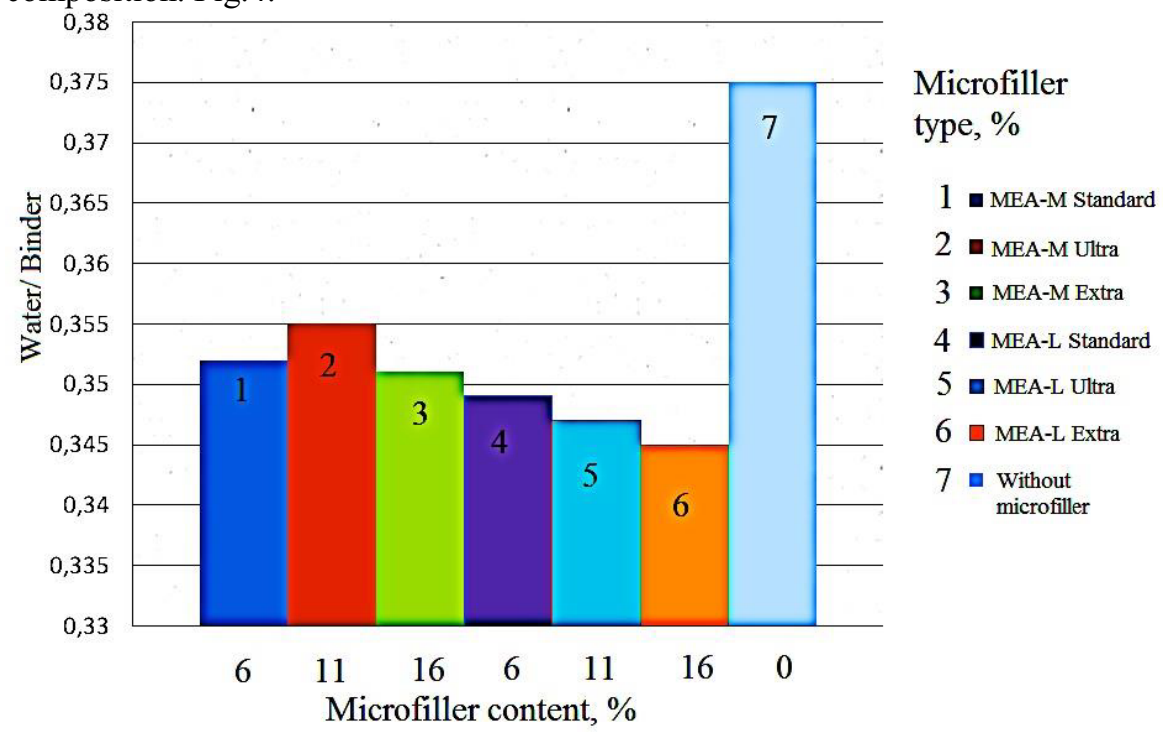

Fig.4. The effect of microfiller on W/C ratio of fine-grained concrete at mix fixed flowability.

As is seen from fig. 4 and 5, fine-grained concrete mixtures based on composite binders with different composition have substantially lower water content as compared to mixtures with basic Portland cement. Considering the presence in composite binders of mineral microfiller possessing high hydraulicity, fine-grained concretes on its basis are characterized with the intense strength gain that reaches $70 \%$ of grade strength within the period of up to 3 days. 


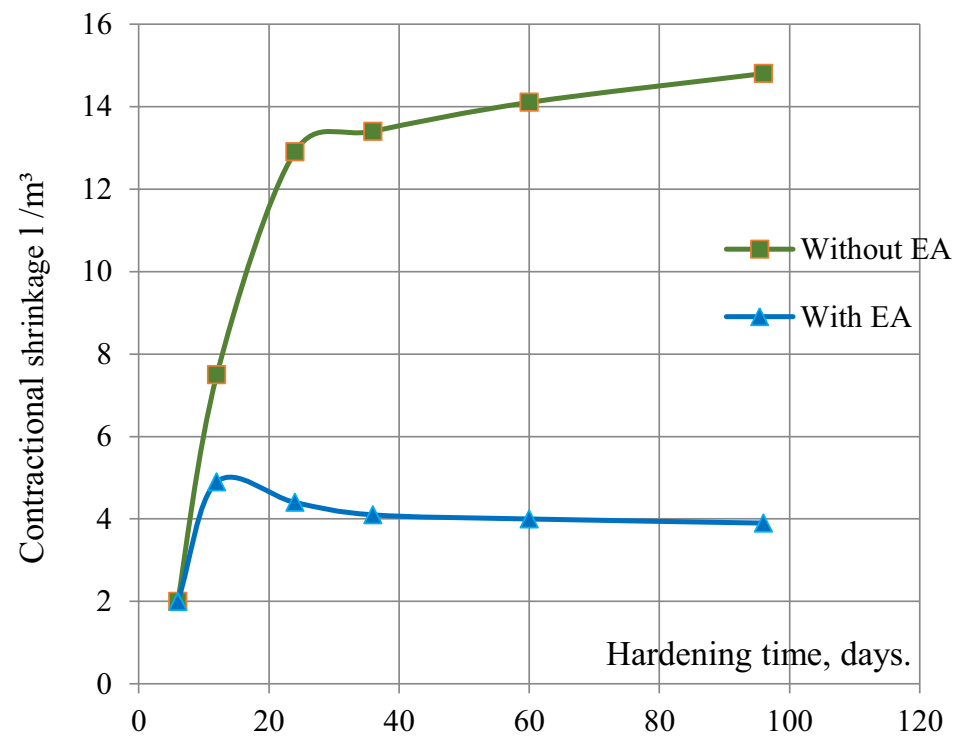

Fig.5. Deformations of fine-grained concrete with expansive component and without it in composition of modified additive.

Fine-grained concretes are intended for erection of cast-in-place concrete and reinforced concrete structures with a wide range of properties with concrete strength class from B30 to B60. Pore structure of modified fine-grained concrete of different production compositions was investigated with the application of mercury porosimetry method. Herewith, it was established that the total pore volume of fine-grained concrete of B50 class amounts 8,91\% with average radius of $0,0501 \mu \mathrm{m}$, for concrete of B40 class total pore volume is $14,12 \%$ with average radius of $0,0646 \mu \mathrm{m}$, and for concrete of B30 class total pore volume amounts $15,13 \%$ with average radius of $0,1205 \mu \mathrm{m}$. Relatively fine-grained structure of fine-grained concrete of different strength classes assumes correspondingly its high durability. In compliance with the accepted procedure the durability of nanomodified fine-grained concrete with production composition was evaluated by weight loss and reduction of dynamic modulus of elasticity after freeze-thawing cycles in water-saturated state at the temperature of $-50{ }^{\circ} \mathrm{C}$. Analysis of the results of freeze-thaw resistance tests demonstrated that the weight loss of fine-grained concrete of all strength classes after 56 freeze-thawing cycles did not exceed $200 \mathrm{~g} / \mathrm{m}^{2}$. Herewith, the value of dynamic modulus of elasticity remained almost unchanged or even increased for 3-8\%. This can be explained with the high content of clincker fund, which is used for recovery of microdestructions of structure at freezing.

Due to elevated content of cement in fine-grained concrete composition in order to eliminate shrinkage impact on its structure and properties, the composition of nanomodified complex additive was added with expansive component on sulfoaluminate basis, which allowed shrinkage reduction for more than 5 times and considerably increase crack resistance of cast-in-place reinforced concrete structures. (Fig.6) The analysis of practical application of expansive cements on the basis of ettringite formation revealed their high 
efficiency at erection of cast-in-place reinforced concrete structures made of fine-grained concrete.

Thus, at construction of sewage facility complex in Varyogan of Nizhnevartovsk district of the Tyumen Region the main objective of application of expansive cement was the secured achieving of design impermeability to water and durability of erected structures. Expansive cement that was used for manufacturing of cast-in-place structures was made by means of mixing of commercial Portland cement and expansive additive at the ratio of $85: 15$. Expansive additive was made by means of mixing of $70 \%$ of aluminate cement and $30 \%$ of calcium sulfate dihydrate. Concrete with expansive additive after 28 days had the following characteristics: expansion value of $0,4 \%$, compression strength of $48 \mathrm{MPa}$, self-stressing or expansion pressure at single-axis restraint of expansion process amounted $1,8 \mathrm{MPa}$. Concrete was placed at air temperature of up to $-20^{\circ} \mathrm{C}$. Sodium nitrate in the amount of $7 \%$ of mixing water was used as anti-freezing admixture. Herewith, compression strength after 7 days was about $13 \mathrm{~N} / \mathrm{mm}^{2}$, and after 28 days it was $25 \mathrm{MPa}$. The analysis of concrete quality after 15 years of operation of sewage facilities demonstrated that all reinforced concrete elements and joints of expansive concrete do not require any repairs and are in operating condition.

The advantages of expansive concrete (high impermeability to water, durability, crack resistance) were used at construction of the number of sports facilities.

For instance, in 2000...2002 was build a sports complex in Gubkinsky, the YamalNenets Autonomous District, with a slab with the area of $1800 \mathrm{~m}^{2}$ made of self-stressing reinforced concrete. Herewith, the requirements to quality of concrete works at erection of reinforced concrete slab were rather high: roughness of $<1,0 \mathrm{~mm}$; high crack resistance under thermal stresses; minimum number of expansion joints on surface etc. Due to high percentage of slab reinforcement - more than $10 \%$, at application of common concrete there was a risk of cracking at stress concentration due to development of shrinkage and thermal strain. Herewith, an effective measure against cracking within the reinforced concrete structures is the concrete prestressing. However, conventional methods of prestressing of reinforced concrete structures were inapplicable for relatively thin slab (14 $\mathrm{cm}$ ) with large area. In this connection it was decided to apply concrete on the basis of expansive cement providing plain stress condition, i.e. self-stressing of reinforced concrete slab.

Prepared expansive cement had self-stressing index of 1,45 $\mathrm{MPa}$ and 28-day compression strength at free hardening of $48 \mathrm{MPa}$, as well as bending tensile strength of 6,0 MPa. These indices corresponded to design requirements. Concrete composition and technological activities for concrete placing were defined during preliminary studies of slab models with the size of $0,14 \times 2 \times 6 \mathrm{~m}$. Concrete (containing $560 \mathrm{~kg} / \mathrm{m}^{3}$ of expansive concrete and quartz sand with the humidity of $5 \%$ in the quantity of $1360 \mathrm{~kg} / \mathrm{m}^{3}$, water: $2801 / \mathrm{m}^{3}$, plasticizer C-3 in the amount of $0,5 \%$ of weight oa expansive cement). Placed concrete was cast into the formwork without additional compacting, manually floated and after placing covered with polyethylene film. Concrete works were performed continuously on a three-shift basis. Placing of fresh concrete was performed by staggered strip method. After placing of a strip $2 \mathrm{~m}$ wide, the next strip was left empty and was concreted in $10 \div 20$ hours depending on temperature. Due to unfavorable climatic conditions (air temperature during night was up to $+5{ }^{\circ} \mathrm{C}$, and during day in sunny weather under the film it was up to $+50^{\circ} \mathrm{C}$ ) the concrete surface after 24 hours was covered with a high-absorbent material. As a result of this treatment it was possible to avoid serious temperature gradient across the cross-section of reinforced concrete slab and to provide wet storage necessary for expansive concrete. Measurements performed during 28 days showed the expansion of 4,1 $\mathrm{mm}$ for reinforced concrete slab $35 \mathrm{~m}$ long. Herewith, tendon stressing amounted $16 \mathrm{MPa}$, stress from concrete prestressing in longitudinal direction amounted $0,84 \mathrm{MPa}$, and in 
transverse direction - 0,93 MPa. After 28 days the compression strength was determined, which amounted $52 \mathrm{MPa}$. Reinforced concrete slab made of expansive cement after 15 years of operation and up to the present day is in good condition.

Due to severe operating conditions related to high static and dynamic loads, high hydrostatic pressure, agressivity of ground water, very high demands are placed on the quality control of concrete and reinforced concrete structures and tunneling and metro engineering. Ten-year experience demonstrates that expansive cements and concretes on their basis may also be used for this purpose with high efficiency.

\section{Conclusions}

It was established that the introduction of microfiller with independent hydraulicity and optimized grain-size and mineral composition to composite binder facilitates the reduction of water demand of composite binder, and respectively, of fine-grained concrete on its basis. Introduction to composite binder of microdisperse expansive additive allows substantial decrease of shrinkage value with simultaneous increase of crack resistance, impermeability to water, freeze-thaw resistance and strength of self-compacting finegrained concretes. The analysis of the results of production implementation of selfcompacting fine-grained concretes with expansive mineral microfiller demonstrated high technical-and-economic efficiency of their application.

\section{References}

1. B. Craeye, G. De Schutter, B. Desmet, J. Vantomme, G. Heirman, L. Vandewalle, Ö. Cizer, S. Aggoun, E.H. Kadri, Cem. and Conc. Res., 40, 6 (2010)

2. M. Bouasker, P. Mounanga, P. Turcry, A. Loukili, A. Khelidj, Cem. and Conc. Comp., 30, 1 (2008)

3. B. Craeye, G. De Schutter, B. Desmet, J. Vantomme, G. Heirman, L. Vandewalle, Ö. Cizer, S. Aggoun, E.H. Kadri, Cem. and Conc. Res., 40, 6 (2010)

4. M. Bouasker, P. Mounanga, P. Turcry, A. Loukili, A. Khelidj, Cem. and Conc. Comp., 30, 1 (2008)

5. F. Han, L. Li, Sh. Song, J. Liu, Powd. Techn., 315 (2017)

6. R. Martinez-Lopez, J. Escalante-Garcia, Const. and Build. Mat., 119 (2016)

7. F. Han, R. Liu, D. Wang, P. Yan, Therm. Act., 586 ( 2014)

8. K. Lee, H. Yoon, K. Yang, Con. and Buil. Mat., 146 (2017)

9. Mehdipour, K. H. Khayat, Cem. and Conc. Comp., 78 (2017)

10. F. Lollini, E. Redaelli, Luca Bertolini, Cem. and Conc. Comp., 46 (2014)

11. O. Larsen, V. Naruts, Mag. of Civ. Eng.(in , 8 (2016)

12. A. Adamtsevich, S. Pashkevich, A. Pustovgar, Magazine of Civil Engineering (in Russian - Inzhenerno-stroitelnyj zhurnal), 3 (2016)

13. Q. Yu, H. Brouwers, Cem. and Conc. Comp., 34, 9 (2012)

14. R. Magallanes-Rivera, C. Juarez-Alvarado, P. Valdez, J. Mendoza-Rangel, Cons. and Build. Mat, 37 (2012)

15. V. Soloviev, A. Eremin, D. Eliseev, A. Buryanov, Building materials (in Russian Stroitelnye materialy), 1-2 (2017) 